\title{
Sensor and Signal Quantification for Blast Furnace Gas Distribution Control ${ }^{*}$
}

\author{
By Tadaaki IWAMURA,** Hiroshi SAKIMURA,** Yunosuke MAKI,** \\ Takanari KAWAI** and Yuichiro ASANO***
}

\section{Synopsis}

Gas distribution control has remarkably contributed to the stabilization of blast furnace operation and the improvement in efficiency. In Kawasaki Steel Corporation sensors for gas distribution control and their quantification have been developed.

In this report the following items are described.

1) Survey of the sensors for gas distribution control.

2) Quantification of gas temperature distribution and gas component distribution by use of discriminant function analysis.

3) Three types of burden profile meter newly developed by Kawasaki Steel Corporation.

4) Their correspondence to actual blast furnace operation both macroscopically and microscopically.

Above mentioned sensors were used effectively in actual blast furnace operation. Efficient and stable operation of blast furnaces have been kept in Kawasaki Steel Corporation.

\section{Introduction}

One of those which have greatly contributed to the stabilization in blast furnace operation and the improvement of efficiency in recent years is gas distribution control. The cohesive zone as well as the detail of gas distribution have been pursued on the basis of blast furnace dissection survey and the analysis of furnace phenomena beginning from that investigation, and besides, the progress in various sensors have facilitated the confirmation of them in the operating furnace.

Furnace gas distribution has great influence upon the three major functions of a blast furnace: heat exchange, permeability and chemical reduction. In particular, it greatly contributes to the utilization of blast furnace $\mathrm{CO}$ gas. ${ }^{1)}$

As for its control, the burden distribution in the radial direction (the layer ratio distribution of ore and coke) provides a manipulated variable for the

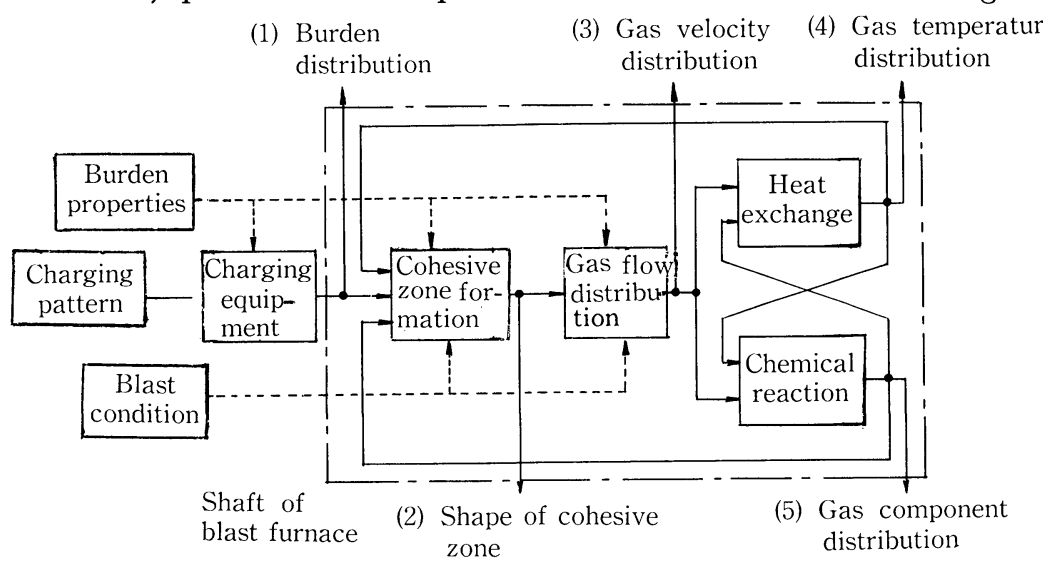

Fig. 1.

Process information about gas distribution in the furnace.

\footnotetext{
* Based on the paper presented to the symposium of the 102nd ISIJ Meeting, October 1981, at Kyoto-fu Chusho Kigyo Kaikan, Kyoto, (published in Tetsu-to-Hagané, 67 (1981), A121, in Japanese). English manuscript received March 18, $1982 . \quad$ C) 1982 ISIJ

** Chiba Works, Kawasaki Steel Corporation, Kawasaki-cho, Chiba 260.

*** Research Laboratories, Kawasaki Steel Corporation, Kawasaki-cho, Chiba 260.
} 
process informations (1) to (5), (4) and (5) are used in the actual operation, and they are fed back to the charging pattern according to operator's judgement.

The measuring method of these informations will be summarized in the following.

\section{Measurement of Burden Distribution}

It is carried out in order to directly measure the results of burden distribution control, a manipulated variable. As shown in Fig. 1, that determines the basis of gas distribution when viewed from the operation. Therefore, we regard that measurement to be important and developed the profile meter. The details will be described later.

\section{Measurement of Cohesive Zone Shape}

Since the shape of a cohesive zone determines gas distribution in a blast furnace, it is desired to measure that shape as directly as possible. Up to the present, the following have been reported as an indirect measuring method: the method of estimation on the basis of the information on shaft pressure, ${ }^{2)}$ the method of estimation from a multi-cylindrical model of blast furnace on the basis of furnace top gas distribution, ${ }^{3}$ ) and so on. On the other hand, the method of measuring the remaining length of a special wire charged from the furnace top, ${ }^{4)}$ the method of measurement from the length and temperature of a sheathed thermocouple charged from the furnace top, ${ }^{5)}$ etc. have been reported as direct measuring methods. Howev$\mathrm{er}$, in an indirect measuring method, verification is a problem, while in a direct measuring method the problem remains that information may not be obtained at any time during normal operation because of batch measurement. Since concrete ideas for the sensor that can be used as a process instrument are poor at the present, such a sensor is to be regarded as one of the most important targets of development in the future.

\section{Measurement of Gas Velocity Distribution}

When gas distribution is directly measured in the form of flow velocity distribution, the He tracer method, ${ }^{6)}$ the heated thermocouple method, ${ }^{7)}$ the method by a fluid flow meter ${ }^{8)}$ or a turbine meter, ${ }^{9)}$ and other different methods have been reported, but they are not yet sufficient from the view points of maintenance, data reproductivity, etc.

We have tried the method by a turbine meter, but the stream line on burden is not stable, so we have obtained merely data with much variation. It may be necessary to consider the method of measurement in the burden and the method of measurement in noncontact.

\section{Measurement of Gas Temperature Distribution}

Gas temperature distribution is measured by a horizontal probe at the furnace top or in the upper section of the shaft. This method is employed in the process of almost all blast furnaces partly because the cost for measurement is low. The fixed type above burden is most popular because it is simple in structure and continuous measurement is feasible. It is not rare that fixed probes are installed in more than 2 directions in consideration of the deviation in the circumferential direction. It is necessary to take into account the temperature fall at the time of charging, and data should be sampled in consideration of charge timing. In the case of measurement while travelling by means of a horizontal probe, the inaccuracy which is caused by heat transfer of a thermometer should be considered, and it is necessary to fix the quantity of gas suction and set up a radiation shield. ${ }^{10)}$ Besides, in the case of measurement inside the burden, not only the gas temperature but also the difference of burden temperature in the radial direction have to be taken into account.

\section{Gas Component Distribution}

As in the case of gas temperature distribution measurement, gas component distribution is also measured by a horizontal probe at the furnace top or in the upper section of the shaft, but the latter is better because the influence of charging is little. However, the abrasion of the probe and clog of sampling tube by dust should be seriously considered. Although it is sufficient if $\mathrm{CO}$ and $\mathrm{CO}_{2}$ can be measured as measurement items, the gas chromatograph is used from the viewpoint of accuracy.

\section{Other Sensors}

The infrared thermo camera is used to see the temperature distribution on the burden surface heated by gas, ${ }^{11)}$ and the furnace top ITV is used to observe the behavior of burden in the furnace. ${ }^{12)}$ They serve to visually comprehend whether or not the burden redistribution, that is, slide of peripheral burden to the center, the movement of the highest temperature part, or the velocity of gas flow at the furnace top is proper, and especially, the furnace top ITV is more effective because of the low cost and ability of supervising the circumstances of charging for each chute rotation in the case of bell-less type charging system, and because it is possible to expand the system to a profile meter to be described later. In both cases, the expansion of the visual area and the quantification of information are the problems to be solved in the future.

Moreover, shaft pressure and stave thermal load are important informations for macroscopically judging gas distribution, and they are used in daily operation.

\section{Gas Distribution Control and Its Quantifica- tion at No. 6 Blast Furnace of Chiba Works}

The No. 6 blast furnace of Chiba Works employed a bell-less charging apparatus for the first time as a large blast furnace in Japan. It achieved the world record at that time in fuel ratio, $418.4 \mathrm{~kg} / \mathrm{t}$-pig, in March, 1980. In 1981, in addition, it achieved the world record in annual coke ratio, $457.9 \mathrm{~kg} / \mathrm{t}$-pig, as all-coke operation. These records were obtained owing to the excellent burden distribution function of the bell-less charging apparatus, and to effective uti- 
lization of various sensor informations to obtain optimum gas distribution at any time.

\section{Gas Distribution Sensor and Burden Distribution Control}

Figure 2 shows the arrangement of the sensors for gas distribution at the No. 6 blast furnace and the configuration of control devices. ${ }^{13)}$ (1) a fixed temperature probe, (2) a shaft horizontal probe, and (3) a furnace top camera were installed when the blast furnace was blown in, and (4) a furnace top ITV and (5) a furnace profile meter were installed in the course of operation. The operation of burden distribution control is based on the combination of (a) the change of charging pattern, (b) change of the stock line, and (c) change of charging start sequence (selection of the timing of ore charging following coke charging or after the descending of the ore level). ${ }^{14}$ ) As for the bell-less charging pattern, several basic patterns are filed in the computer, as shown in Fig. 2 , and the operator determines the pattern to be used and the timing when it is used. These basic patterns are arranged in accordance with presupposed gas distribution, namely sequentially from central flow promotion to peripheral flow promotion, thus, they are contrived to facilitate operator's selection.

The bell-less charging system features its large degree of freedom, and it is important to arrange it properly and limit it appropriately.

\section{Operational Circumstances and Gas Distribution Control}

Figure 3 shows the operation progress since the blow in of the No. 6 blast furnace, and as to three typical operational circumstances, it shows also typical charging patterns in these periods. The operational circumstances in periods A, B and C, respectively, can be summarized as follows:

A: On account of excessive central flow, the peripheral side became inactive and unreduced ore fell onto the top of the tuyere, so that the trouble of "tuyere bending" such that the tuyere was crashed took place frequently. (Extreme internal operation)

B: On account of excessive peripheral flow, the peripheral side became too active, so that unstable
PLC: Programmable Logic Controller

$\mu$-CPT: $\mu$-computer

Fig. 2. Instrumentation for gas flow control at the top of Chiba No. 6 blast furnace.

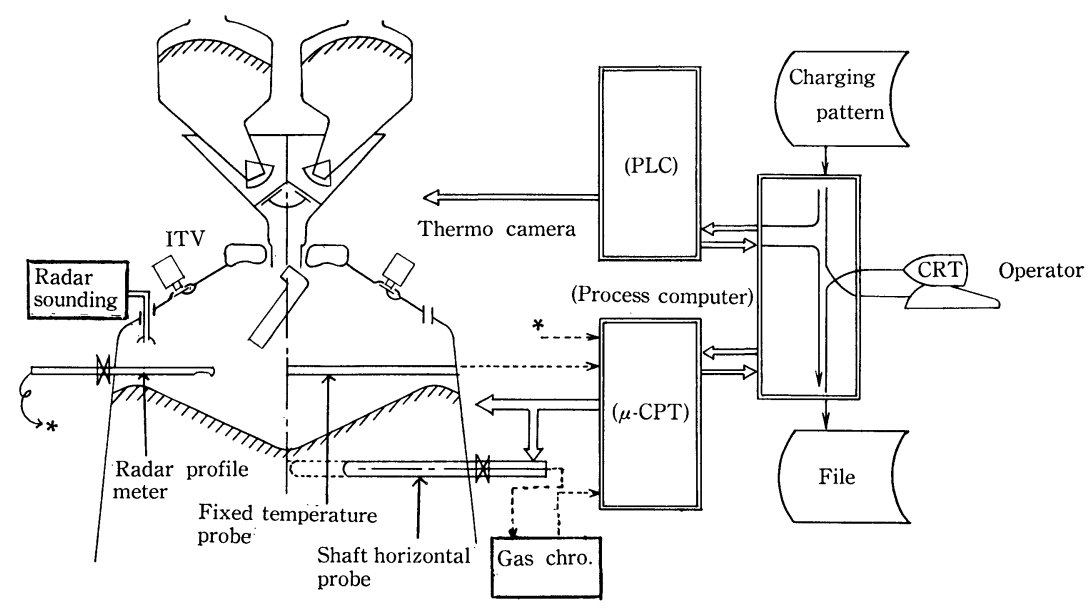

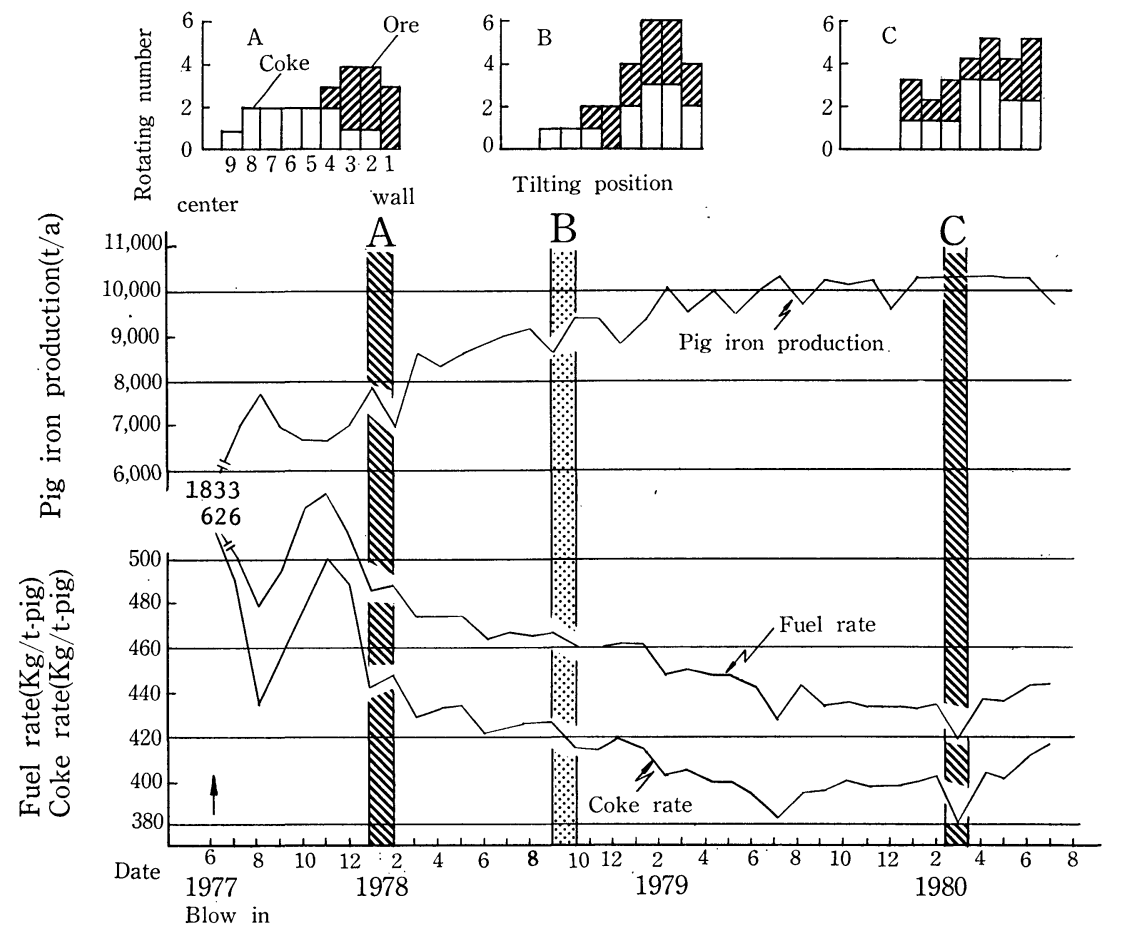

Three distinct operating conditions

A: Too intensive central flow operation $\rightarrow$ Frequent tuyere bending

B: Too intensive peripheral flow operation $\rightarrow$ Frequent tuyere failure

G: Optimum gas distribution $\rightarrow$ World's record of low fuel rate

Fig. 3.

Operational progress of Chiba No. 6 blast furnace. 

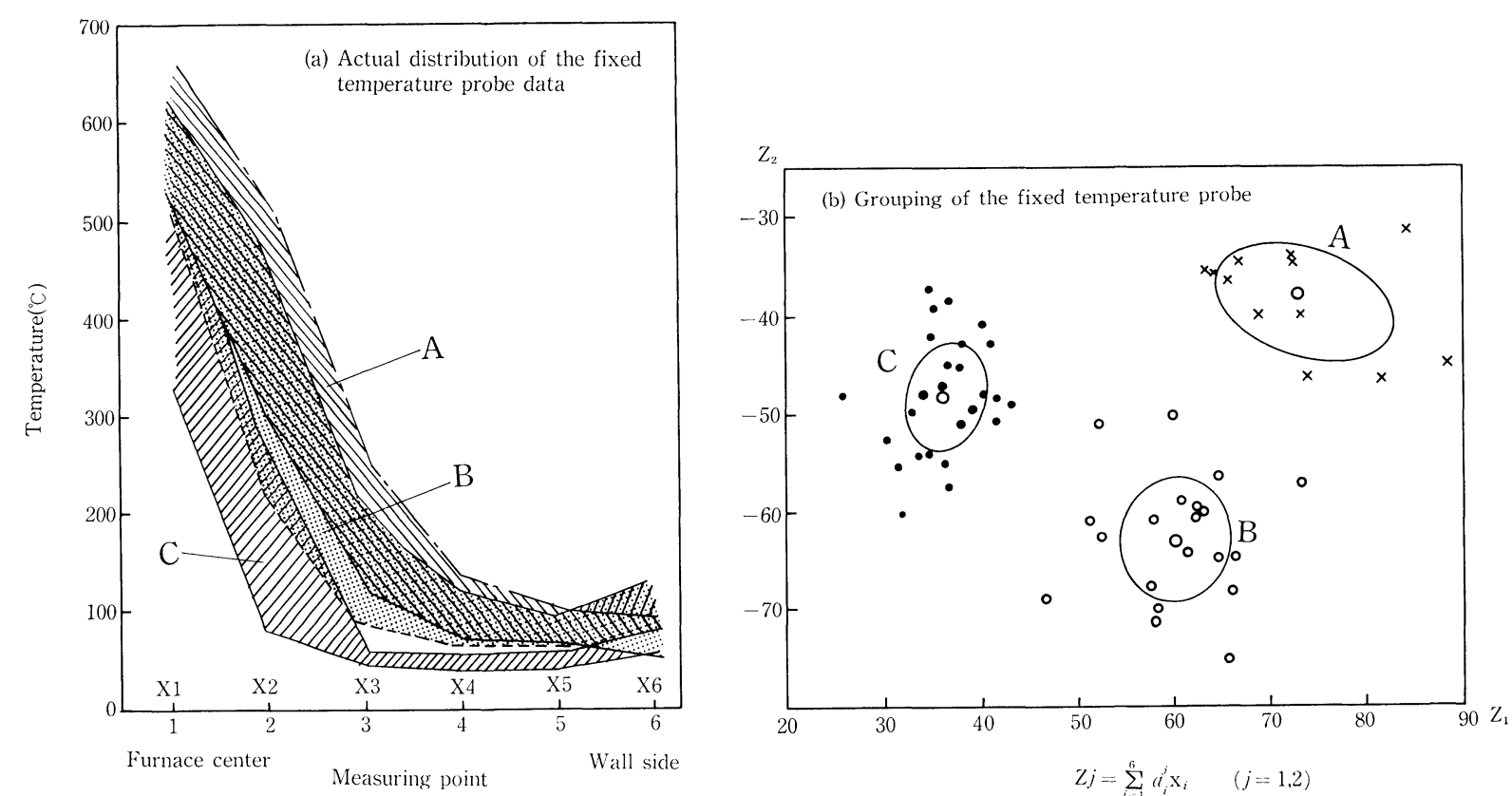

Fig. 4. Gas flow distribution of Chiba No. 6 blast furnace and their data processing by discriminant function analysis.

permeability and tuyere burn-out were frequently caused. (Extreme external operation)

G: A high blending $(97 \%)$ test of processed ore ratio was performed, and a monthly fuel rate of $418.4 \mathrm{~kg} / \mathrm{t}$-pig was obtained. (Optimum operation)

The gas distribution in each of these periods was supervised on the basis of the data obtained by means of a fixed temperature probe and a shaft horizontal probe. The temperature profile in each period is shown in Fig. 4(a). The figure shows the pattern in a mean value of one day, but the dispersion within each period and the duplication between periods are so large that it is difficult to make use of it as clear information. Moreover, since it is pattern information, with no quantitative expression, we cannot regard it as objective information.

\section{Quantification of Pattern Information by Discriminant} Function and Its Utilization as Operational Guide

In Fig. 4(b), the above-described data in each period is divided into groups by the method of discriminant function which is one of the methods of multi-variable analysis. ${ }^{15}$ ) Gas temperature distribution is completely grouped, and the obscurity in the above-mentioned pattern information has disappeared. Figure 5 shows its procedure where the pattern information is represented by multi-variable $\mathbb{X}$, the transfer matrix $A$ which maximizes the ratio of the variance between groups to the variance within groups is given in order to obtain discriminant vector $\mathbb{Z}$. Thus, pattern information is transformed into a point in $\mathbb{Z}$ space so as to discriminate which group the data belong to easily.

Discrimination is performed by calculating normalized distance from average point of each group in $\mathbb{Z}$ space. This distance can be calculated by the following equation:
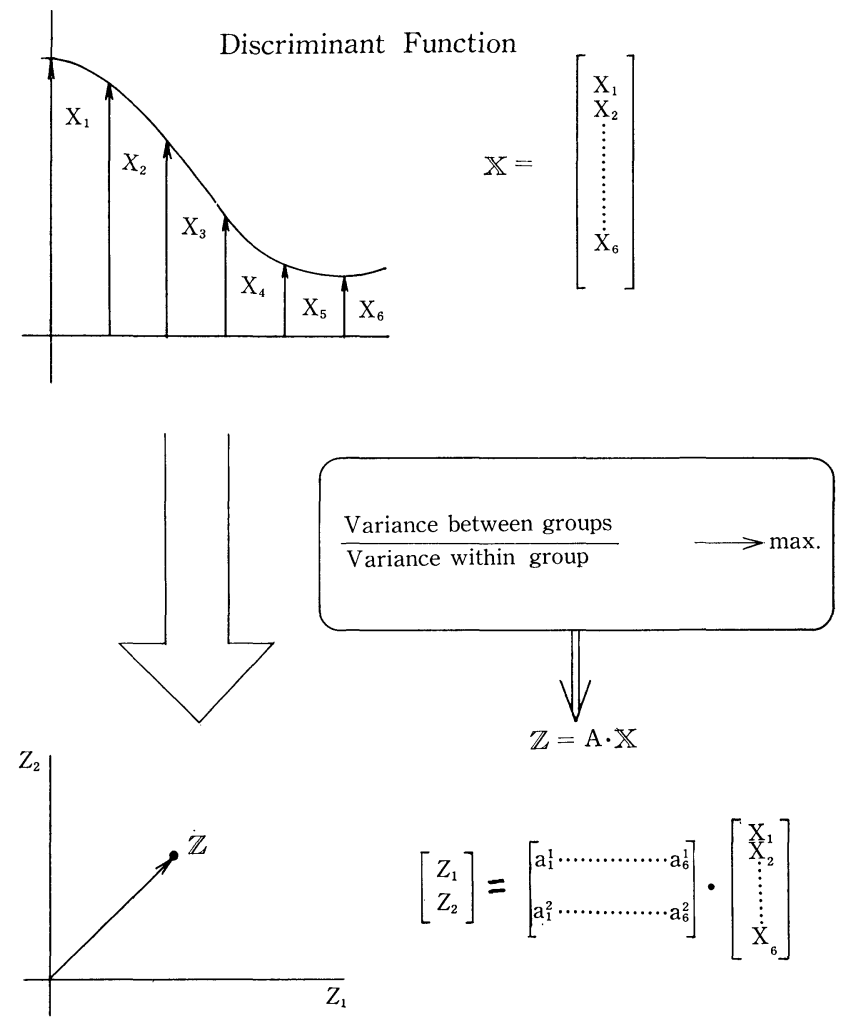

Fig. 5. General procedure of discriminant function analysis.

$$
D_{j}=\left(\mathbb{Z}_{i}-\mathbb{Z}_{j}\right)^{t} V_{j}^{-1}\left(\mathbb{Z}_{i}-\mathbb{Z}_{j}\right)
$$

where, $\mathbb{Z}_{i}$ : Projection of the current gas distribution

$\mathbb{Z}_{j}$ : Mean value of groups $\mathrm{A}, \mathrm{B}$ and $\mathrm{C}$

$V_{j}$ : Variance matrix of groups $\mathrm{A}, \mathrm{B}$ and $\mathrm{C}$.

In Fig. 6, this is grouping of gas component distribution, the movement of gas distribution from periods $\mathrm{A}$ to $\mathrm{C}$ through $\mathrm{B}$ and after period $\mathrm{C}$ is plotted in the discriminant space of gas component distribution. The fine dotted line in this figure is the actual result of the rate of gas utilization. 


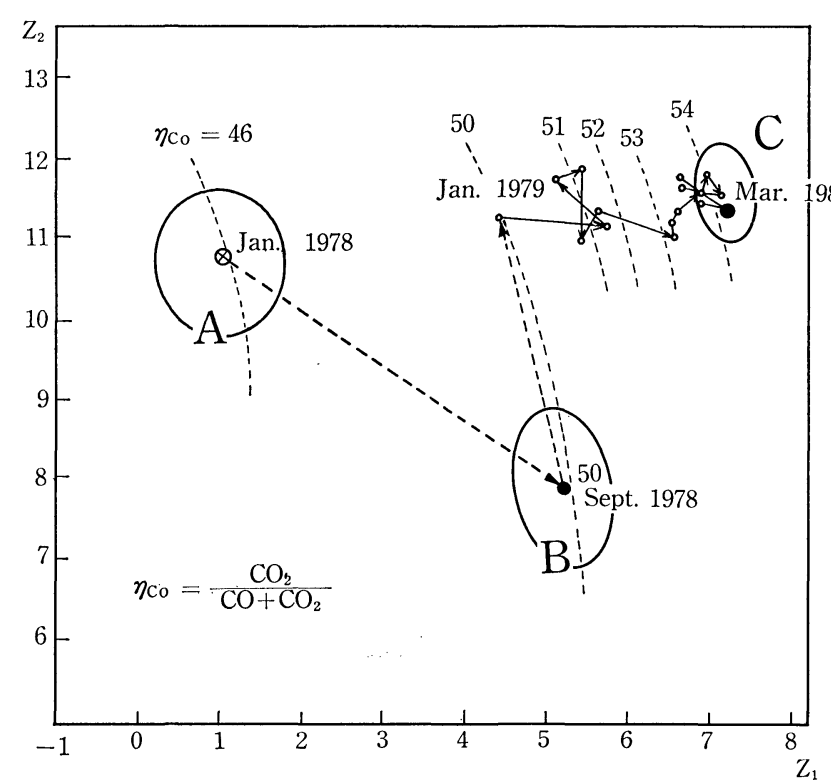

Fig. 6. Moving of the operational data on $z_{1}-z_{2}$ plane.

It started from $\mathrm{A}$ and finally arrived at an optimal point $\mathrm{C}$ by trial and error.

Figure 6 can be regarded to be an operational guide picture concerning gas distribution. By reflecting daily gas distribution information on this figure and by controlling the distances from A, B and $\mathrm{C}$, it is possible to apart from the unfavorable circumstances (A and B) experienced in the past so far as possible and to approach the point $\mathrm{G}$ where the optimum operation in the past experiences can be given.

\section{Knowledge by Discriminant Function Method}

The arrangement of the knowledge obtained in the course of this analysis results in the following:

(1) The pattern information of both gas component and gas temperature can distinctively be grouped by this method and can be quantified. These two kinds of information are enough for the daily control of gas distribution.

(2) Although both of gas component distribution and gas temperature distribution are effective for the estimation of gas distribution, the latter which is not under the influence at the charging time has less dispersion within groups.

(3) Table 1 shows the eigen vector of the discriminant function in Fig. 4. In the case of the temperature probe the values of the central part of the furnace are small. This means that the data of the central part of the furnace have large dispersion and have less contribution to grouping, and that the information of the peripheral part is more important. In the case of gas component information, on the other hand, all data contribute to grouping appropriately.

(4) It was confirmed that this method was effective not only for the grouping in the case where the operating conditions such as A, B and C differ greatly from one another, but also the grouping in the case where the operating conditions resemble one another.

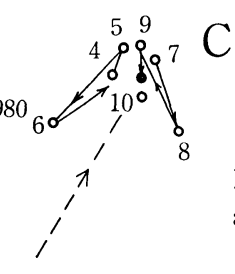

Moving of operational data after arriving to the optimum point.

Table 1. Evaluation of measuring points by discriminant function analysis.

(a) Fixed Temperature Probe

\begin{tabular}{|c|c|c|c|c|c|c|c|}
\hline \multirow{2}{*}{ 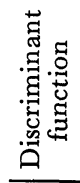 } & \multicolumn{6}{|c|}{ Eigen vector } & \multirow{2}{*}{ 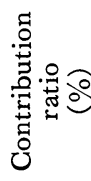 } \\
\hline & $a_{1}$ & $a_{2}$ & $a_{3}$ & $a_{4}$ & $a_{5}$ & $a_{6}$ & \\
\hline$z_{1}$ & 0.04 & 0.01 & 0.07 & -0.19 & 1.00 & -0.35 & 75.1 \\
\hline$z_{2}$ & 0.00 & -0.02 & 0.18 & -0.77 & 1.00 & -0.83 & 24.9 \\
\hline
\end{tabular}

(b) Horizontal Shaft Probe

\begin{tabular}{|c|c|c|c|c|c|c|c|c|}
\hline \multirow{2}{*}{ 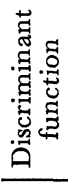 } & \multicolumn{7}{|c|}{ Eigen vector } & \multirow{2}{*}{ 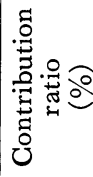 } \\
\hline & $a_{1}$ & $a_{2}$ & $a_{3}$ & $a_{4}$ & $a_{5}$ & $a_{6}$ & $a_{7}$ & \\
\hline$z_{1}$ & 0.43 & -0.27 & 0.40 & 1.00 & 0.16 & -0.45 & -0.13 & 86.4 \\
\hline$z_{2}$ & -0.78 & 0.09 & 0.67 & 0.52 & -0.15 & -0.11 & 1.00 & 13.6 \\
\hline
\end{tabular}

Genter of the furnace

$Z_{j}=\sum_{i} a_{i}^{j} X_{i}$

\section{Development of Burden Profile Meter}

The burden profile information is a direct output from the burden distribution control equipment as illustrated in Fig. 1, and its utilization is very large because the error of the equipment can be evaluated directly, and because it is feedback information with very small delay of time in the whole system. We have put emphasis upon this information from the early time, developed three types of profile meter as shown in Table 2, and obtained good results from each of them. At the present, we are concluding the relationship between the measured data and actual blast furnace operation, and these data are already effectively used by the blast furnace operators.

\section{Construction of Profile Meter and Circumstances of Mea- surement}

\section{Mechanical Profile Meter}

Its aim was the development in a short period of time. At the beginning, it was installed at the No. 2 blast furnace of Chiba Works, ${ }^{16)}$ and then it was improved to shorten the measuring time at Mizushima Works. ${ }^{17)}$ The principle diagram of the instrument is shown in Fig. 7. The weight is vertically moved-up and down while moving the lance in the radial direction of the furnace, and the depth at 12 points in the 
radial direction is measured in $40 \mathrm{sec}$. Its greatest features are simplicity in the principle and low cost of the instrument. Figure 8 shows an example of measurement recorded on an $X-Y$ recorder. This

Table 2. Comparison of three types of burden profile meter.

\begin{tabular}{|c|c|c|c|}
\hline & $\begin{array}{l}\text { Mechanical } \\
\text { type }\end{array}$ & $\begin{array}{l}\text { Micro wave } \\
\text { type }\end{array}$ & Laser type \\
\hline Principle & $\begin{array}{l}\text { Weight }+ \\
\text { Lance }\end{array}$ & $\begin{array}{l}\mu \text {-wave }+ \\
\text { Lance }\end{array}$ & $\begin{array}{l}\text { Ar laser }+ \\
\text { ISIT* camera }^{*} \text { came }\end{array}$ \\
\hline Function & $\begin{array}{l}12 \sim 13 \text { points } \\
\text { for one radial } \\
\text { direction }\end{array}$ & $\begin{array}{l}\text { Continuous } \\
\text { measuring for } \\
\text { one radial } \\
\text { direction }\end{array}$ & $\begin{array}{l}\text { Continuous } \\
\text { measuring for } \\
\text { a part of } \\
\text { surface }\end{array}$ \\
\hline $\begin{array}{l}\text { Measuring } \\
\text { time for } \\
\text { one radial } \\
\text { direction }\end{array}$ & $40 \mathrm{sec}$ & $1.2 \mathrm{~min}$ & $2 \mathrm{sec}$ \\
\hline Accuracy & $\pm 50 \mathrm{~mm}$ & $\pm 130 \mathrm{~mm}$ & $\pm 50 \mathrm{~mm}$ \\
\hline $\begin{array}{l}\text { Relative } \\
\text { cost }\end{array}$ & 1 & 1.4 & 2.3 \\
\hline $\begin{array}{l}\text { Applied } \\
\text { blast } \\
\text { furnace }\end{array}$ & $\begin{array}{l}\text { Mizushima } \\
\text { Nos. } 2,3 \text { and } \\
4 \mathrm{BF}\end{array}$ & $\begin{array}{l}\text { Chiba } \\
\text { Nos. } 5 \text { and } 6 \\
\text { BF }\end{array}$ & $\begin{array}{l}\text { Chiba } \\
\text { No. } 2 \text { BF }\end{array}$ \\
\hline
\end{tabular}

* ISIT: Intensified Silicon Intensifier Target

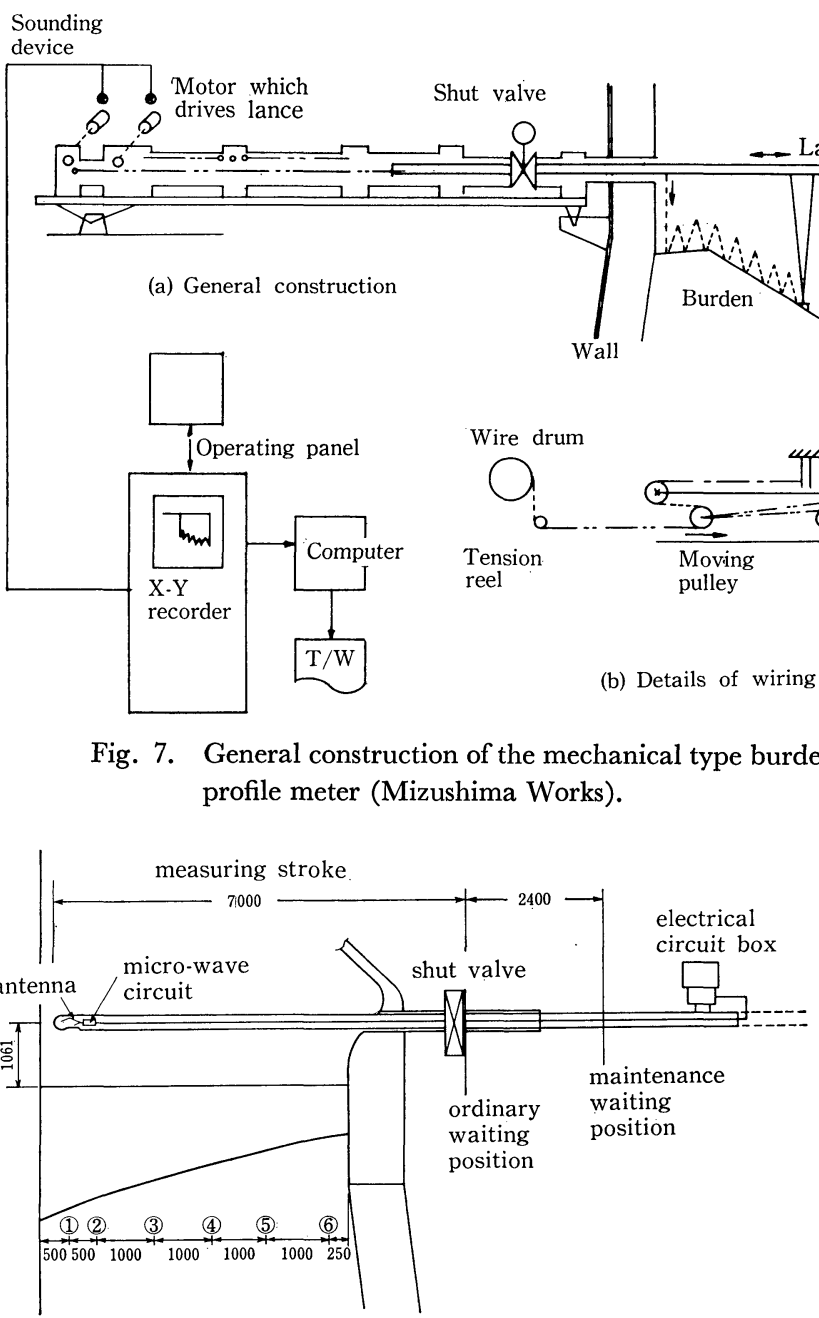

Fig. 9. General construction of the micro-wave type burden profile meter (Chiba No. 6 BF). instrument is connected with a process computer, and several kinds of data processing such as the calculation of layer thickness are carried out on line.

At the beginning of development, there was a problem in the aspect of reliability in the taking-up mechanism of a wire, the tension reel, etc., but the instrument was completed as a practical instrument by the improvement after that.

\section{Micro-wave Type Profile Meter}

It is an expansion of the application of a fixed type micro-wave sounding device. ${ }^{18)}$ The construction is shown in Fig. 9. A reflecting antenna and a microwave circuit are incorporated at the top of the probe, and the antenna size is made as large as possible by employing one-antenna system in order to improve the directivity of the antenna. The frequency of the $\mu$-wave is $8.8 \sim 10.8 \mathrm{GHz}$ and the power is $50 \mathrm{~mW}$. The probe is driven by hydraulic unit, but because of its shortage in power, the measuring time is somehow long: 1.2 min per radius. However, this is not a problem in the principle, and it is possible to increase the speed by the improvement of the hydraulic unit. Figure 10 shows an example of measurement, and

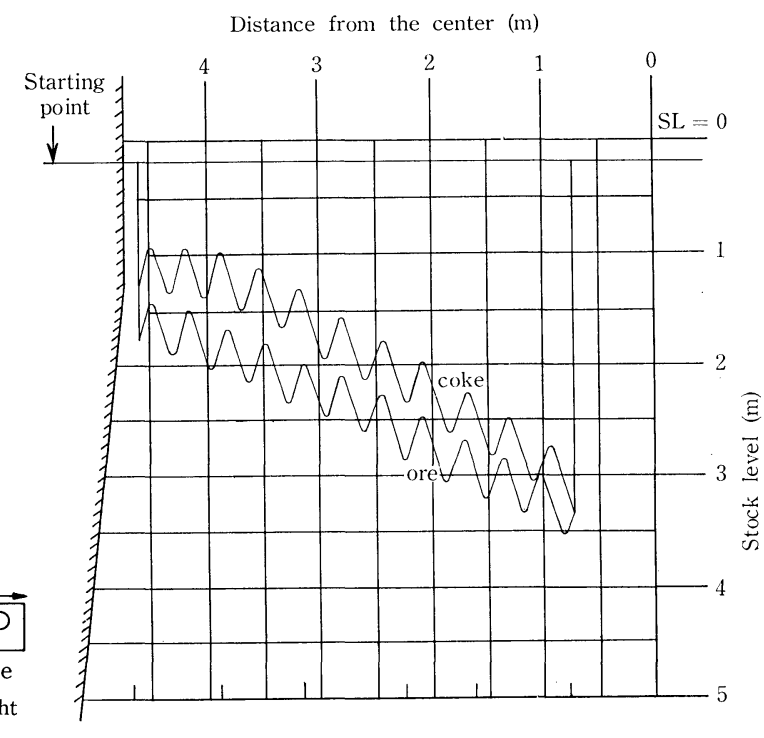

Fig. 8. Measured examples by the mechanical type burden profile meter (Mizushima No. 2 BF).

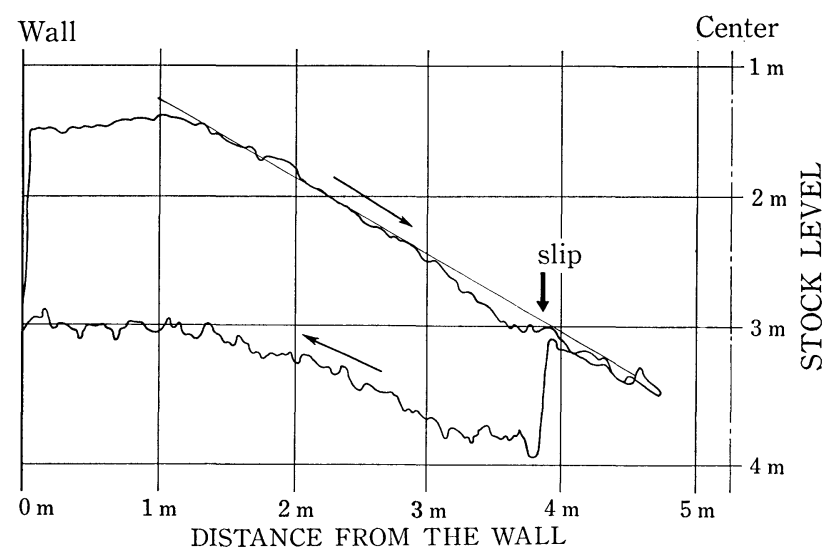

Fig. 10. A measured example by the micro-wave type burden profile meter when a slip of burden was occurred (Chiba No. $6 \mathrm{BF}$ ). 


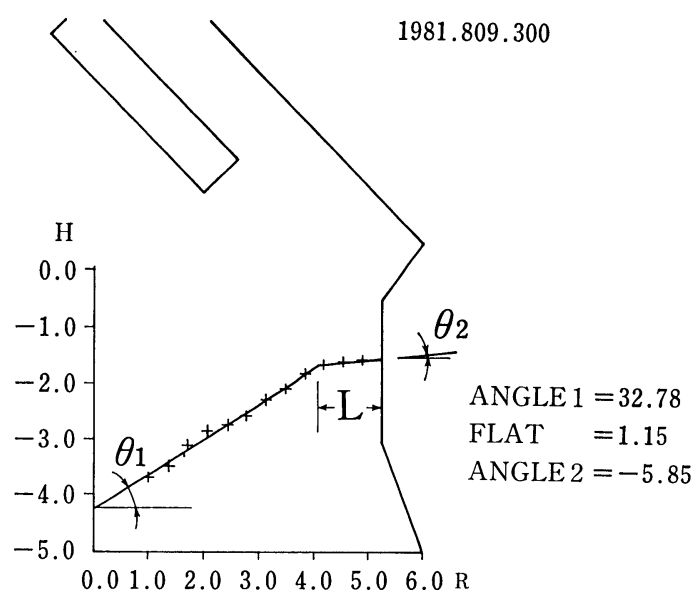

Fig. 11. An example of output display of burden profile and the extraction of the main characteristics of profile (Chiba No. $6 \mathrm{BF}$ ).

Fig. 11 shows an example of the extraction of the main characteristics, $\theta_{1}, \theta_{2}$ and $L$, of the profile processed by the computer. In the case of Fig. 10, though the profile of the forward stroke is normal, slip of burden took place just during the measurement of the backward stroke. The change at that moment is well caught, and it is clear that it functions to the full as a profile meter.

Figure 11 shows approximate expressions on the basis of the measured values at 12 points in the radial direction, and the data analysis to be described later is based on this expression.

In the case of the micro-wave system, the problem of the irregularity of measured values caused by the interference phenomenon of micro-wave on the surface of burden and the measurement of an inclined object by an antenna with insufficient directivity (of approximately $\pm 5 \mathrm{deg}$ ) are the technical key points. Employing the one-antenna system and the various data processing by use of $\mu$-computer could clear the problems, and the system displays its full functions. Its greatest feature is the good maintenance owing to non-contact measurement. For further progress, adopting milli-wave technique will be one of the subjects to be discussed in the future. ${ }^{18)}$

\section{Laser Type Profile Meter}

Its construction is shown in Fig. 12. A profile is obtained by scanning the 4-W Argon laser having a wave length of $0.5 \mu \mathrm{m}$ on the surface of raw material and analyzing the picture caught by an ITV. It features that the measuring time is as short as $2 \mathrm{sec}$ per radius and that the profile measurement of a surface is feasible. ${ }^{19)}$ Technical points are to eliminate the background noise in the high temperature part on the surface of burden and to remove the influence of dust of the furnace gas, and they are cleared by the contrivance of data processing and purge equipment. Figure 13 shows the profile at every rotation of the chute of the bell-less charging apparatus, and the difference of the pile of ore before the third rotation where the tilting angle changes and after the 4th rotation, as well as the redistribution of raw material surface after the 5 th rotation where there is no ore falling

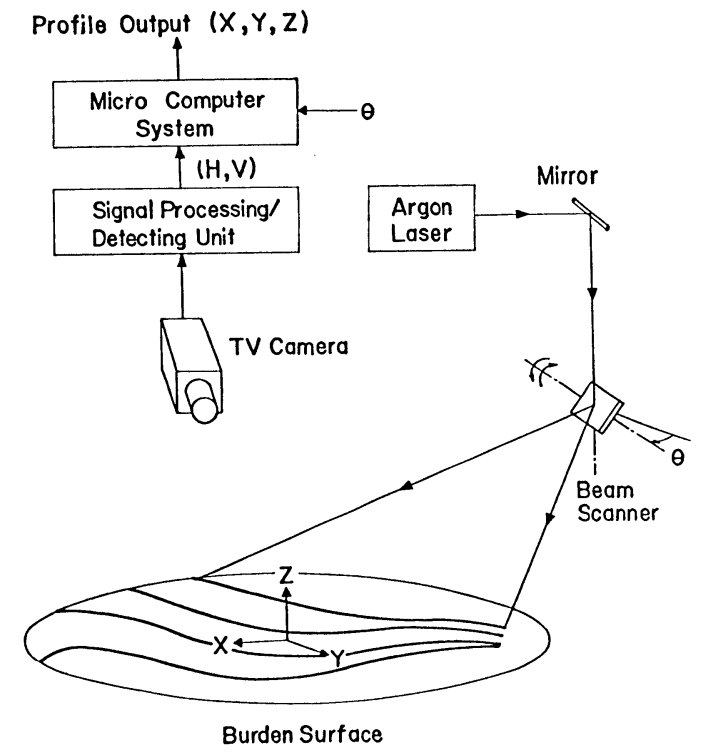

Fig. 12. General construction of the laser type burden profile meter (Chiba No. 2 BF).

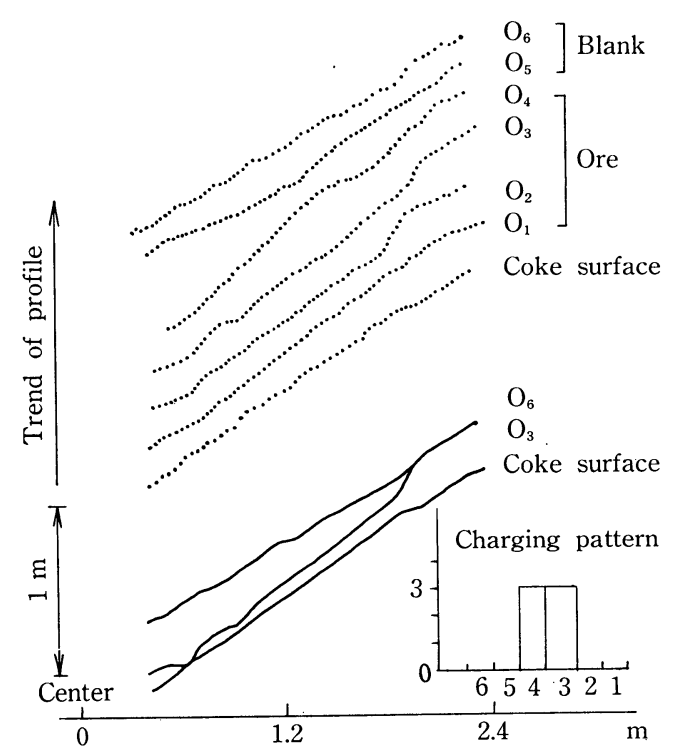

Fig. 13. Measured examples by the laser type burden profile meter (Chiba No. 2 BF). Continuous measuring of ore surface for every rotating of the chute.

in the actuality, can be observed. Figure 14 shows the profile of the surface shape with respect to the $1 / 4$ part of the furnace top surface.

In Fig. 14 burden level is quantized into 20 steps and expressed by 20 different letters and the profile is able to be grasped at a glance.

The high-speed measuring ability of this system is very advantageous for the measurement of the descending velocity of burden and the measurement of layer thickness, and from a functional point of view, this is the most excellent system among the three systems. The problem of cost resulting from the complication of the instrument, the establishment of maintenance technique, and the security of the visual area at a bell type blast furnace will be the subjects in the future. 


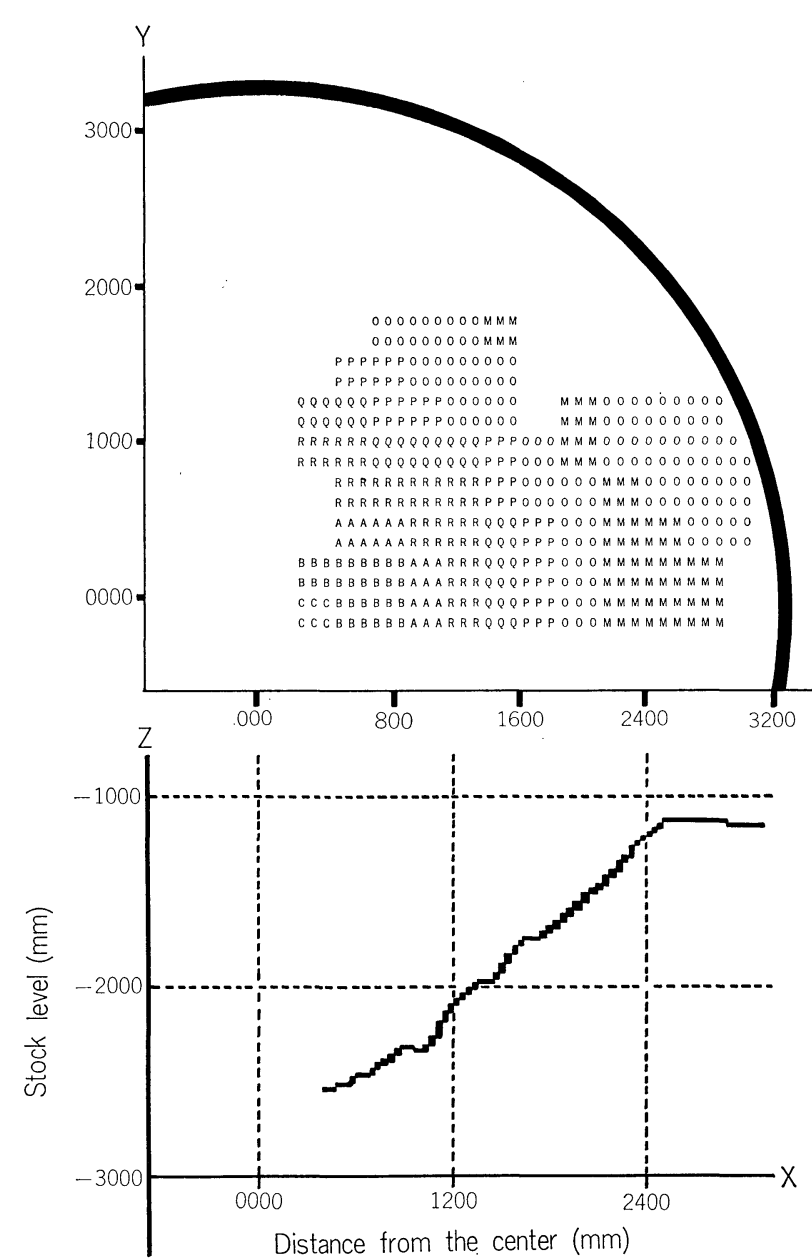

Fig. 14. A measured example by the laser type burden profile meter (Chiba No. 2 BF). (Surface measuring)

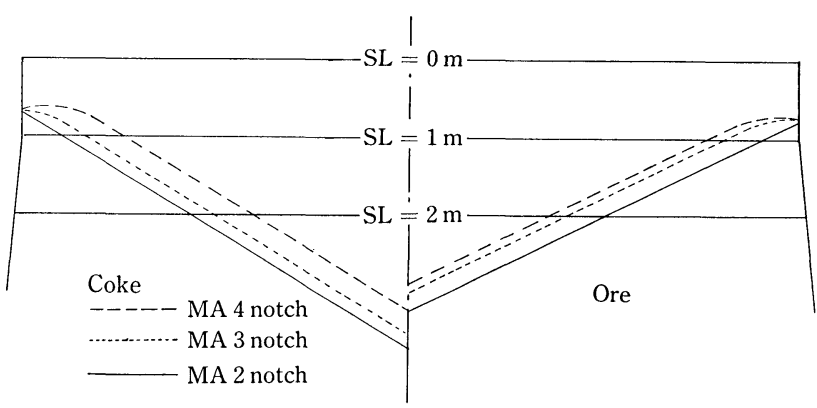

Fig. 15. Movable armor and burden profile (Mizushima No. 2 BF).

\section{Application of Profile Meter to Blast Furnace Operation}

The first application of the profile meter is to confirm whether or not the burden distribution control device is in correct operation, or whether or not the actual burden profile correctly corresponds to a big change of the charging pattern. In the normal operation, however, the change of the pattern is not so big, and moreover, it is often hidden in the dispersion of the actual profile obtained by the same charging pattern. Therefore, the introduction of statistic ideas is indispensable to detailed analysis, and there is not yet any established method. The knowledge we have obtained up to the present is described in the following.

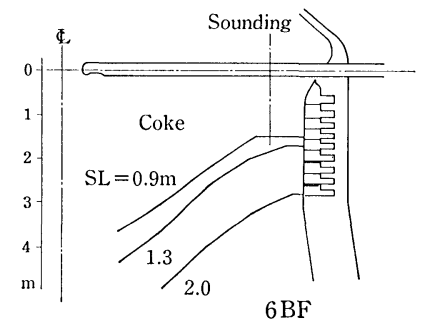

Fig. 16. Stock line and burden profile (Chiba No. 6 BF).

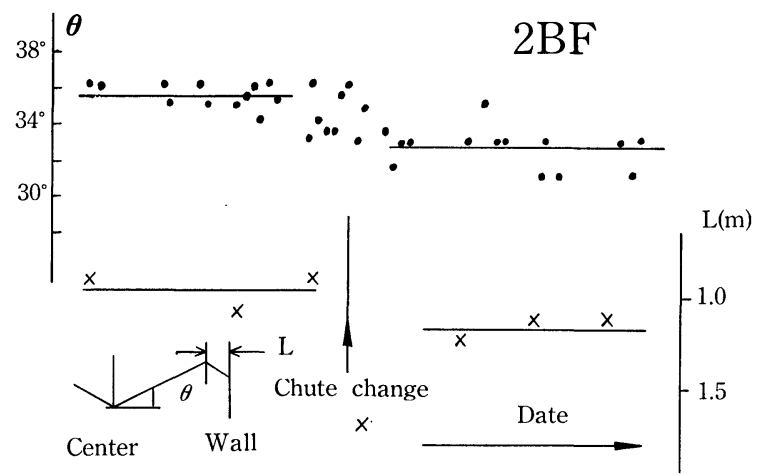

Fig. 17. Variation of burden profile by a chute exchange (Chiba No. 2 BF).

\section{Macroscopic Correspondence to Blast Furnace Opera-} tion

These three profile meters have been using in actual operation, and we observed the dispersion of the profile is comparatively large.

Figure 15 shows the results of the measurement of the movable armor and burden profile at No. 3 blast furnace of Mizushima Works. While the angle of repose does not change so much, the shape of the peripheral part (namely, the position of so-called shoulder part) changes remarkably.

Figure 16 shows the results of measurement of the profile by changing the height of the stock line at No. 6 blast furnace of Chiba Works. In this case, while the charging pattern is kept constant, the shape of the peripheral part changes widely, and thus, an effect similar to the adjustment by the movable armor can be recognized. The function of the adjustment of gas distribution by the stock line can be confirmed by this.

Figure 17 illustrates the angle of repose, $\theta$, as well as the movement of the position of the shoulder part, $L$, at No. 2 blast furnace of Chiba Works before and after the replacement of the rotating chute.

The remarkable changes in both of them were caused by the change of the frictional resistance against burden due to the replacement of the linear of the chute and the deviation of the fitting angle of the chute. As a result, these changes incurred the deterioration of the blast furnace running condition. The example given here demonstrates that the macroscopic change of the burden profile can sufficiently be caught by the profile meter quickly in spite of the dispersion of the very profile. 
2. Correspondence to Fine Adjustment of Charging Pattern

In the normal operation, a big change of the charging pattern as described in the preceding section is rarely performed.

Figure 18 shows three charging patterns of ore selected from among those used recently at No. 6 blast furnace of Chiba Works. Figure 18(a) shows the charging pattern for obtaining the inclination of the central gas flow, and Fig. 18(c) the charging pattern for the inclination of the peripheral gas flow. In both of these, the same charging pattern of coke was used.

The characteristics of the burden profile are represented by three parameters of $\theta_{1}, \theta_{2}$ and $L$, as shown in Fig. 11, and discriminant function analysis is performed, then, the results as shown in Fig. 19 can be obtained. According to the table below, 34 data were discriminated correctly out of total 50 data. So the degree of discrimination was no more than $68 \%$. Although discrimination to some degree is possible, the dispersion within groups as well as the overlapping between groups is comparatively large.

Figure 20 shows the results of the discriminant function analysis of gas temperature distribution by a fixed temperature probe in the same period. It is clear that the discriminant ability has been raised up to $78 \%$. That is to say, though the charging pattern exercises definite influence also upon the burden profile, its influence upon gas temperature distribution (gas flow distribution) is more intensive. This suggests that the change of charging pattern exercises some sort of influence upon the part which cannot be grasped only by the burden profile, and it will be necessary to pay attention in the future, for example, to the formation of the mixed layer of coke and ore or the density or size distribution of burden in the radial direction.

Table 3 shows the eigen vector of the discriminant function in the case of the burden profile. Here, the

(a)

rotation number

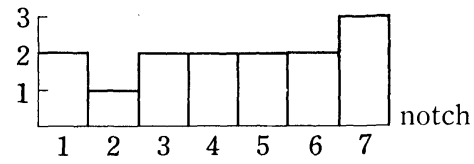

Central

flow

operation

rotation number

(b)

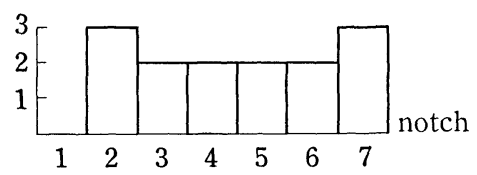

rotation number

(c)

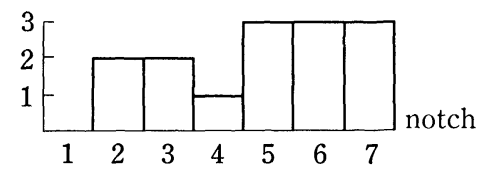

Peripheral

flow

operation

wall side

center

Fig. 18. Three typical ore charging patterns currently used (Chiba No. 6 BF). percentage of contribution of position $L$ in the shoulder part is very high. If more informations than those in Fig. 11 are taken out in order to characterize the burden profile and the discriminant function is applied to them, then the discriminant capability will be raised by $4 \%$ or $5 \%$. Also in this case, it has been recognized that the percentage of contribution of the shape of the peripheral part is large.

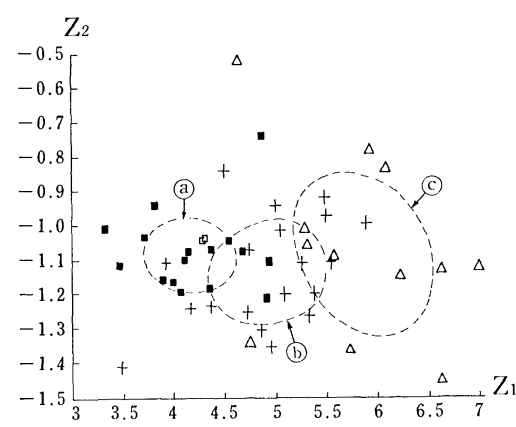

\begin{tabular}{|c|c|c|c|c|c|}
\hline & \multicolumn{3}{|c|}{ Discriminated result } & \multirow{2}{*}{ Total } \\
\hline & & $a$ & $\mathrm{~b}$ & c & \\
\hline \multirow{3}{*}{$\mid \begin{array}{l}\hat{c} \\
\mathrm{c} \\
u \\
\mathrm{a} \\
\mathrm{l}\end{array}$} & a & 13 & 4 & 1 & 18 \\
\hline & b & 1 & 10 & 8 & 19 \\
\hline & $\mathrm{c}$ & 0 & 2 & 11 & 13 \\
\hline \multicolumn{2}{|c|}{ Total } & 14 & 16 & 20 & 50 \\
\hline
\end{tabular}

Fig. 19. Result of discriminant function analysis of burden profile for the three typical ore charging patterns (Chiba No. 6 BF).

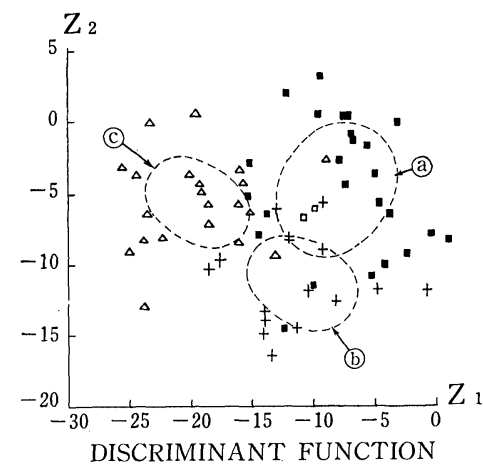

\begin{tabular}{|c|c|c|c|c|c|}
\hline & \multicolumn{3}{|c|}{ Discriminated result } & \multirow{2}{*}{ Total } \\
\hline & & $\mathrm{a}$ & b & c & \\
\hline \multirow{3}{*}{\begin{tabular}{|c|}
$\mathrm{A}$ \\
$\mathrm{c}$ \\
$\mathrm{t}$ \\
$\mathrm{u}$ \\
$\mathrm{a}$ \\
$\mathrm{l}$ \\
\end{tabular}} & a & 20 & 4 & 3 & 27 \\
\hline & b & 3 & 10 & 2 & 15 \\
\hline & $\mathrm{c}$ & 1 & 1 & 19 & 21 \\
\hline \multicolumn{2}{|c|}{ Total } & 24 & 15 & 24 & 63 \\
\hline
\end{tabular}

Fig. 20. Result of discriminant function analysis of gas temperature distribution for the three typical ore charging patterns (Chiba No. $6 \mathrm{BF}$ ).

Table 3. Evaluation of parameters representing burden profile by discriminant analysis.

\begin{tabular}{c|ccc|c}
\hline \multirow{2}{*}{$\begin{array}{c}\text { Discriminant } \\
\text { function }\end{array}$} & \multicolumn{3}{|c|}{ Eigen vector } & \begin{tabular}{c} 
Contribution \\
ratio \\
\cline { 2 - 5 }
\end{tabular} \\
\cline { 2 - 5 } & $a_{\theta_{1}}$ & $a_{L}$ & $a_{\theta_{2}}$ & \\
\hline$z_{1}$ & 0.133 & 1.000 & 0.115 & 98 \\
$z_{2}$ & -0.072 & 1.000 & 0.014 & 2 \\
\hline
\end{tabular}




\section{Summary of Burden Profile Meter}

The arrangement of the above knowledge results in the following:

(1) Any of three types of the profile meters developed by us has so high a degree of reliability that they can be utilized in the actual operation.

(2) The first application of the profile meter is to confirm macroscopic change of the charging pattern, and it fully functions also for the supervision of installational trouble in the burden distribution control apparatus.

(3) The dispersion of the burden profile for the same charging pattern is so large that it is difficult to pursue detailed operation in the normal operation from the profile itself, and it is necessary to introduce a statistic approach such as discriminant function, etc.

(4) What characterizes the burden distribution is the shape of the peripheral part, and the contribution of the "Shoulder" position is the largest.

(5) For the change of the charging pattern which is given in normal operation, gas distribution information such as gas temperature distribution has higher sensitivity than the burden profile. As to what determines gas distribution, attention should be also paid to other information beside the burden profile.

(6) The superiority and inferiority of the three types of profile meters should be decided in consideration of the purpose of application, cost and maintenance, and we have not yet arrived at a determinate conclusion.

\section{Conclusion}

Gas distribution control has significantly contributed to the stabilization of blast furnace operation and the improvement in efficiency.

In addition, it has great influence upon the improvement of the life time of the blast furnace. It is not too much to say that the establishment of this technique has first brought about the process which is at the operator's disposal and can be controlled at a mercy of the operator. However, the very technique still largely depends upon the operator's experience, and we cannot help saying that its objectivity is far from satisfactory. A more effort should be made as to the reliable sensor technique shown in this report and the quantification of the in- formation obtained from it.

\section{REFERENGES}

1) Y. Togino: Bull. Japan Inst. Metals, 17 (1978), 570.

2) Y. Togino, M. Sugata, I. Abe and M. Nakamura: Tetsuto-Hagané, 65 (1979), 1526.

3) H. Itaya, F. Aratani, A. Kani and S. Kiyohara: Kawasaki Steel Giho, 13 (1981), 541.

4) S. Kajikawa, K. Wakimoto, K. Aratani and K. Ishii: Tetsu-to-Hagané, 66 (1980), S38.

5) E. Katayama, M. Tsuchiya, R. Okabe, S. Taguchi, K. Okumura and S. Tamura: Tetsu-to-Hagané, 66 (1980), S682.

6) K. Sano, T. Miyazaki, T. Kamoshida and H. Yoshida: Tetsu-to-Hagané, 62 (1976), S438.

7) Yu. N. Ovchinnikov, Yu. V. Yakovlev, V. B. Shcherbatskii, N. A. Spirir and V. S. Novikov: Steel in USSR, (1978), No. $5,245$.

8) K. Sano and T. Miyazaki: Tetsu-to-Hagané, 66 (1980), S36.

9) Asada Research Laboratories and Kakogawa Works, Kobe Steel Ltd.: The 76th Instrumentation Committee of the Joint Research Society, ISIJ, (1980), No. 76-1-8.

10) A. Furushiro, A. Kawasaki and T. Kajihara: Int'l Federation of Automatic Control Congress VIII, Int'l Federation of Automatic Control, Kyoto, Aug. 1981, Paper No. 88.5.

11) Y. Togino and N. Okubo: 38th Ironmaking Conference (ISS-AIME), Mar. 1979, 295.

12) T. Tamiya, T. Iwamura, I. Shimonishi, H. Takahashi and J. Mori: Keiso, 23 (1980), No. 2, 12.

13) T. Nagai, T. Iwamura, H. Sakimura, T. Tamiya, H. Kubo and H. Marushima: Trans. ISIJ, 20 (1980), 54.

14) K. Okumura, T. Kawai, H. Marushima, H. Takahashi and J. Kurihara: Tetsu-to-Hagané, 66 (1980), 1956.

15) T. Iwamura, T. Tamiya, H. Sakimura, T. Kawai and H. Kubo: Int'l Federation of Automatic Control Congress VIII, Int'l Federation of Automatic Control, Kyoto, Aug. 1981, Paper No. 87.4.

16) T. Nagai, J. Kurihara, H. Takahashi, K. Okabe and M. Koudo: McMaster Symposium, McMaster Univ., Hamilton, (1978).

17) K. Akimoto, S. Nakaji, H. Horita, O. Nishimura and Y. Oka: Tetsu-to-Hagané, 66 (1980), S29.

18) T. Iwamura, M. Kusunoki, H. Sakimura, T. Tamiya, K. Nakashima and A. Takeda: IMEKO 9th World Congress, Int'l Measurement Confederation, Berlin (West), 1982, Paper No. 15.2.

19) Y. Asano, T. Yabe, K. Kurita, A. Momose, A. Hirahashi and S. Moriya: Tetsu-to-Hagané, 66 (1980), S681. 